Article

\title{
Two-Step Manufacturing Process Measurement Model Using Qualitative and Quantitative Data-A Case of Newbuilding Dry-Docking
}

\author{
Denis Rabar ${ }^{1, *}$, Danijela Rabar ${ }^{2} \mathbb{D}$ and Duško Pavletić ${ }^{1}$ \\ 1 Faculty of Engineering, University of Rijeka, Vukovarska, 51000 Rijeka, Croatia; dusko.pavletic@riteh.hr \\ 2 Faculty of Economics and Tourism "Dr. Mijo Mirković", Juraj Dobrila University of Pula, Preradovićeva 1/1, \\ 52100 Pula, Croatia; drabar@unipu.hr \\ * Correspondence: denrabar@gmail.com; Tel.: +385-914-390-311
}

Citation: Rabar, D.; Rabar, D.;

Pavletić, D. Two-Step Manufacturing

Process Measurement Model Using

Qualitative and Quantitative Data-A Case of Newbuilding Dry-Docking. J. Mar. Sci. Eng. 2021, 9, 464. https:// doi.org/10.3390/jmse9050464

Academic Editors: Jin Wang and Mihalis Golias

Received: 24 March 2021

Accepted: 23 April 2021

Published: 25 April 2021

Publisher's Note: MDPI stays neutral with regard to jurisdictional claims in published maps and institutional affiliations.

Copyright: (c) 2021 by the authors. Licensee MDPI, Basel, Switzerland. This article is an open access article distributed under the terms and conditions of the Creative Commons Attribution (CC BY) license (https:// creativecommons.org/licenses/by/ $4.0 /)$.

\begin{abstract}
Newbuilding dry-docking is a part of the shipbuilding manufacturing process, common for vessels built on slipways. The subject of this research is steel-built vessels intended for nonrestricted sea-going navigation. Based on former experience, the necessity of the dry-docking projects measurement has been noted as a managerial tool for performance estimation and project comparison. The dry-docking project is a complex task which includes the first self-propelled sea passage and the transfer of the manufacturing process to a remote place. The dry-docking result is a surveyed and coated vessel ready for sea trials and five-year service until the next dry-docking. This paper deals with a model which enables process measurement using the analytic hierarchy process (AHP) method for qualitative data related to the dry-docking places and data envelopment analysis (DEA) for quantitative data related to the vessels' technical and cost data. The modelled data are collected from the completed dry-dockings, and the twenty-nine studied vessels represent the decision-making units (DMU) used in two-step process measurement calculations. The obtained results can distinguish the efficient DMUs, which create an efficient frontier as benchmarks or "the best practice units" in the given DMU set. For the non-efficient DMUs, the efficiency score and rate of improvements needed to reach the efficient frontier will be calculated, and the sources of inefficiency will be recognized.
\end{abstract}

Keywords: shipbuilding; process measurement; multi-criteria decision making; data envelopment analysis; analytic hierarchy process

\section{Introduction}

This paper introduces the newbuilding dry-docking performance measurement model as a process efficiency indicator, and consequently, a helpful decision tool for operations management. This model includes efficiency ranking using quantitative and qualitative data.

Newbuilding dry-docking is a part of the shipbuilding process, which is situated at the end of the process when the vessel is substantially completed, outfitted and seaworthy. The vessels described in this paper were built on the slipway, longitudinally launched, and berthed on the outfitting pier for final outfitting and commissioning. All the studied vessels have steel as their building material and are sea-going with unrestricted navigation. A vessel is subjected to dry-docking when substantially completed and seaworthy.

The dry-docking operation commences with the vessel transfer from the shipbuilding shipyard to the repair shipyard which has dry-dock facilities. The subjected vessel is then lifted up from the water in order to enable working activities. The dry-docking consists of the various activities related to the ship's outer shell works and inspections, such as fouling scraping, steelwork (includes launching supporting structure chipping), high pressure washing, spot sand blasting as well as sand sweeping, and coating system application which includes antifouling coating application. The appendages and equipment checks 
are related to propeller shaft wear-down measurement and sealing check, as well as rudder stock bearings and jumping bar clearances measurement. The dry-docking is also the opportunity to fit the underwater sensors such as speed log, echo sounder and draught sensors. During the dry-docking, the vessel is subjected to final ship systems commissioning and testing in order to be ready for sea trials after dry-docking completion. The dry-docking operation is completed when the vessel is afloat again, released by the dry-dock facility, and free to sail away.

The dry-docking period could be also an opportunity to complete some unresolved jobs remaining from the shipbuilding shipyard. Therefore, the number of crew members could be increased during the dry-docking, consequently increasing expenses. It needs to be emphasized that working activities in shipyards are more effective than the same activities in the dry-dock due to transport, logistics and accommodation cost increase.

The result of the newbuilding dry-docking is a seaworthy vessel with a surveyed, clean and coated outer shell prepared to proceed to the sea trials, particularly the speed and manoeuvring trials, and after the vessel's delivery to the buyers, is ready for a five-year service before the subsequent dry-docking.

The vessels' dry-dockings studied in this paper were carried out with two types of vessels in an almost equal stage of completion. They were dry-docked in four different dry-docks in different seasons. The dry-docking duration is a variable parameter. These conditions have an impact on the dry-docking result. The dry-docking/vessel's data were collected on site, at the dry-docking location. One of the authors of this study observed all twenty-nine studied dry-dockings in the capacity of superintendent.

From the managerial point of view, to measure the success and set the targets of a particular vessel dry-docking and to determine "the best practice vessel(s)" among the dry-docked vessels sample is a complex mission. To overcome the target setting problem, the dry-docking project for each particular vessel has to be simplified and described as a process with its inputs and outputs.

The analysis of the already completed dry-dockings is the base for the "ex post" decision making, locating the best practice vessels, and giving the data for forecasting the behaviour of the vessels to be dry-docked in the future in order to make their dry-dockings improved in a successful and efficient manner.

The capability to transform the inputs into outputs is called efficiency. A decisionmaking unit (DMU) represents each entity included in the analysis. Any DMU capable of reaching more output with an equal quantity of inputs or to reach the same output with less input is considered more efficient. In the context of this paper, the vessel is to be taken as a DMU.

In addition to the studied vessels, the dry-docking places are going to be evaluated by their characteristics depending on meteorological and logistics conditions, as well as the working conditions and damages which occurred during dry-dock operations.

The purpose of this paper was to create a dry-docking performance measurement model as the managerial tool for the best technical performance identification among the present DMUs. This model could also be used as a forecasting tool for future vessels' dry-dockings.

The model used will exploits analytic hierarchy process (AHP) method in ranking the alternatives based on the set decision criteria. AHP deals with the qualitative data linked to the dry-docking facilities, whereas the data envelopment analysis (DEA) methodology is the main performance measurement method using qualitative data. DEA uses nonparametric data (only the relation within the same data category is needed). There is no need to express the explicit relation between the process inputs and outputs. The inputs and outputs are chosen at the discretion of the expert/researcher, and the DEA calculates the weights of the input/output parameters in order to reach the maximum efficiency scores for each DMU. 


\section{Literature Review and Methodology}

The various decision-making examples are going to be presented in the literature review. This will be followed by the brief methodology introduction.

\subsection{Literature Review}

The findings from the literature review show the necessity of research which measures the dry-docking project efficiency, sorts out the efficient ones, and establishes the peers for the inefficient ones considering the vessel's technical and cost parameters, as well as the managerial opinion on the considered projects.

Kaune [1] wrote an exhaustive description of the dry-docking operations commencing with the dry-dock preparation, the vessels entering dry-dock, working activities progress, the completion of dry-dock jobs, and a vessel's departure from dry-dock. House [2] made a comprehensive description of the dry-dock types and dry-docking operations. In the literature studying the dry-docking process measurement and target setting, there is Naffisah et al. [3], using the artificial neural network in order to obtain a mathematical model of dry-docking maintenance duration estimation, considering the volume and type of activities to be carried out during the dry-docking. The data mining method was used by Surjandari et al. [4] for dry-docking duration estimation. The dry-docking duration estimation model using the numerical ant-colony decision tree algorithm was introduced by Surjandari et al. [5]. Apostolidis et al. [6] developed the dry-docking cost estimation based on the equation model which expresses the dry-docking cost as a relation among the ship's type, size and age parameters. The relation between the vessel's data such as deadweight, age and type, and dry-docking time and labour was researched by Dev and Saha [7]. The necessity of a vessel's dry-docking aiming to reach the vessel's top performance in relation to the maximum speed and minimum fuel consumption was described by Koboević et al. [8]. The assessment of the key performance indicators for the Bay of Bengal shipbuilding industry has been introduced by Gavalas et al. [9]. To assess the performance and competitiveness of the active shipyards in this area, this study used three MCDM (multi-criteria decision making) methods, the fuzzy DEMATEL (decisionmaking trial and evaluation laboratory), the fuzzy ANP (analytic network process), and the MOORA (multi-objective optimization on the basis of ratio analysis).

An analysis covering twelve Chinese repair shipyards using the DEA method was carried out by Yang et al. [10]. This research consisted of two complementary parts where the first one studied ship repair facilities comparison and the second one added staff data to the first comparison data set. Establishing performance targets as well as efficiency measurement using the DEA method on a set of repair shipyards engaged in ferry fleet repair was introduced by Mayo et al. [11]. The DEA methodology was used by Rabar et al. [12] on a quantitative data set for the dry-docking efficiency assessment. The results pointed to benchmarks for the dry-docking performance and the guidelines to future dry-docking improvements on the researched data set. The use of the AHP method in ship repair can be found in Mous [13], analysing Korean repair shipyards' competitiveness among other repair shipyards world-wide.

An integrated DEA/AHP method literature survey revealed two comprehensive reviews done by Ho [14] and Ho et al. [15]. Among the other methods, the integrated AHP/DEA method has been mentioned in a limited number of papers studying manufacturing, supplier selection and efficiency measurement. Sinuany-Stern et al. [16] and Feng et al. [17] gave the indication that DEA performance could be improved by integrating the DEA/AHP ranking model. The search for the DEA/AHP method dealing with dry-docking performance gave no results. The DEA/AHP method use can be found in other engineering fields such as manufacturing plant layout optimization studied by Yang and Kuo [18] and Arunyanart and Pruekthaisong [19]. For the manufacturing plant layout optimization purposes, the AHP method was used for qualitative data ranking and the DEA method for layout efficiency calculations. Korpela et al. [20] introduced the integrated DEA/AHP model for warehouse operator selection, using AHP for customer 
preferences ranking and DEA for warehouse operators cost and service effectiveness scores. Sevkli et al. [21] and Zhang et al. [22] used the DEA and AHP methods for supplier selection, combining qualitative and quantitative data. Park and Lee [23] introduced the combined DEA/AHP approach in supplier selection and stepwise benchmarking. The DEA was deployed for efficiency measurement, while AHP was used for importance assessment. The sewer pipeline failure risk assessment using the DEA / AHP methodology combined with the Geospatial Information System resulted in the model developed by Ghavami et al. [24]. The DEA was used for quantitative data calculation and AHP was used for experts' judgement analysis. In the shipping business, Chen, A., and Zheng, P. [25] introduced the DEA/AHP ship-targeting model for ship supervision which merged decision makers' subjective judgments and qualitative data.

Sueyoshi et al. [26] studied the audit prioritization model based on the DEA/AHP method. In the created model, the managerial opinion was used as qualitative data, and the business data were used as quantitative data for the organization systematic assessment.

Wang et al. [27] introduced the integrated DEA/AHP method in order to overcome the AHP limitations in dealing with a high number of alternatives (hundreds or thousands) and used the advantage of the DEA method to carry out the calculations with a high number of alternatives in bridge structures assessment.

The literature review resulted in no paper on the dry-docking/newbuilding performance and/or efficiency measurement based on the DEA/AHP integration. There is an obvious research gap in such project manufacturing processes, and this paper could participate in filling this gap.

\subsection{DEA Methodology}

The data envelopment analysis (DEA) methodology was originally proposed by Charnes et al. [28]. DEA is a linear programming-based non-parametric technique which evaluates the relative efficiency of the operating entities, called decision-making units (DMUs) that possess a homogenous set of empirical data divided into inputs and outputs. Through the DEA calculations based on existing DMUs, an efficient frontier is established containing the efficient DMUs with an efficiency score equal to 1 and considered best practice units. Other DMUs, with an efficiency score less than 1, lie outside the efficient frontier and are considered inefficient. The degree of inefficiency is calculated in relation to the distance between the inefficient DMU and the efficient frontier and attributed to input excesses as well as to output shortfalls.

There are two basic models that are used for efficiency calculation purposes in this paper-the CCR (named after Charnes, Cooper and Rhodes) model proposed by Charnes et al. [28], and the BCC (named after Banker, Charnes and Cooper) model proposed by Banker et al. [29]. The returns to scale upon which the model is built could be assumed to be either constant (CCR model) or variable (BCC model).

The DEA model could be oriented to input reduction or to output augmentation. This paper will deal with the output-oriented models, which corresponds to the management intention to reduce dry-docking expenses. The DMU efficiency could be expressed as the ratio between outputs and inputs:

$$
\text { efficiency DMU }=\frac{\sum_{r=1}^{S} u_{r} y_{r}}{\sum_{i=1}^{m} v_{i} x_{i}},
$$

where: $y_{r}=$ output $r, u_{r}=$ output $r$ weight, $x_{i}=$ input $i v_{i}=$ input $i$ weight.

DEA is basically used for relative efficiency measurement and evaluation, benchmarking, target setting and identifying the best practice. The main value-added potential of the DEA methodology is in the simplified display of the underperforming DMUs, its ability to point the peers as potential efficiency improvement targets, and calculate the inefficient DMUs projections to the efficient frontier in order to quantify the improvements needed to reach the efficient frontier for each particular inefficient DMU. 
In accordance with Cooper et al. [30], a set of $n$ DMUs is considered $\left(D M U_{j}, j=1,2, \ldots, n\right)$, and each of them produces $s$ outputs using $m$ inputs. Let the $x_{j}=\left\{x_{i j}, i=1,2, \ldots, m\right\}$ represent the input vector, and $y_{j}=\left\{y_{r j}, r=1,2, \ldots, s\right\}$ the output vector of $D M U_{j}$. The data set is determined by the input matrix $X=\left(x_{i j}, i=1,2\right.$, $\ldots, m, j=1,2, \ldots, n)$, and output matrix $Y=\left(y_{r j}, r=1,2, \ldots, s, j=1,2, \ldots, n\right)$.

The DEA model basic principle lies in the efficiency assessment of $D M U_{0}, o \in$ $\{1,2, \ldots, n\}$, and consists of seeking for virtual DMUs with inputs and outputs defined as the linear combination of inputs and outputs of the remaining DMUs in a given DMU set, namely $X \mu$ and $\gamma \mu, \mu=\left(\mu_{1}, \mu_{2}, \ldots, \mu_{n}\right)$, where $\mu>0$ corresponds to the proportions contributed by efficient DMUs to the projections of $D M U_{o}$ onto an efficient frontier. Seeking the virtual DMU could be generally formulated as a standard linear programming problem:

Output oriented model:

$$
\max _{\eta, \mu}
$$

subject to:

$$
\begin{gathered}
X \mu \leq x_{o} \\
\eta y_{o}-\gamma \mu \leq 0 \\
\mu \geq 0 \\
e \mu=1
\end{gathered}
$$

while $e$ is a row vector with all elements equal to 1 . The virtual DMU needs to be better (at least not worse) than $D_{0}$.

The constraints (2) to (5) create the DEA CCR model, and the DEA BCC model is created using constraints (2) to (6). The Equations (7) and (8) express the input excesses and the output shortfalls, i.e., "slack" vectors:

$$
\begin{aligned}
& t^{-}=x_{o}-X \mu \\
& t^{+}=\Upsilon \mu-\eta y_{o}
\end{aligned}
$$

where the efficiency $\theta$ is expressed as

$$
\theta=\frac{1}{\eta}
$$

A $D M U_{0}$ is considered efficient if the optimal solution $\left(\eta^{*}, \lambda^{*}, t^{-*}, t^{+*}\right)$, as a result of maximizing $\eta$ and minimizing sum of $t^{-*}$ and $t^{+*}$, reaches $\theta^{*}=1$ and $t^{-*}=0, t^{+*}=0$, otherwise it is not efficient.

The CCR efficiency $\theta_{C C R}^{*}$ is called technical efficiency, and the BCC efficiency $\theta_{B C C}^{*}$ is called pure technical efficiency. Technical efficiency (CCR) is a measure of inputs transformation into outputs, relative to the maximum potential calculated which creates the efficiency frontier. The pure technical efficiency (BCC) measures the local efficiency and solely represents the managerial capabilities to organize the process carried out in each DMU.

The advantages of the DEA methodology are: (i) it is a non-parametric approach; (ii) its inputs and outputs could be chosen according to researcher and/or process demands; (iii) the model's adaptability to the management strategy (orientation to input reduction or output augmentation); (iv) the model's adaptability in relation to the return to scale (constant or variable); and (v) that expert opinion on input and output weights is not necessary because the model itself assigns the best set of weights to each observed DMU, and thus avoids the subjective assessment and contributes to the objectivity of analysis. The DEA limitations are: (i) sensitivity to missing data; (ii) extreme data readings; and (iii) data collection errors. The advantages and limitations were referred to in the literature by Coelli et al. [31], Moritmer [32], Coelli et al. [33], Kahraman [34], Velasques and Hester [35], Aruldoss et al. [36], as well as Korhonen and Wallenius [37]. 
According to Banker et al. [38], the number of DMUs researched has to be at least three times higher than the sum of inputs and outputs in order to obtain proper DMUs discrimination. Using the DEA method follows the recommendation regarding data preparation, as recommended by Sarkis [39] and Dyson et al. [40]. Undesirable outputs are treated as recommended by Gollany et al. [41], Lovell [42] and Liu [43]. The general formulation of the DEA model follows the recommendations of Cook et al. [44]. The DEA calculation is carried out by DEASolverPro7 software package.

\subsection{AHP Methodology}

The AHP is a multi-criteria decision making (MCDM) method developed by Saaty [45]. It is intended to decompose a complex MCDM problem into a hierarchy structure, and then assess the relative importance of decision criteria by pairwise comparison. In the next step, the decision alternatives are compared to each particular criterion, determining an overall priority for each decision alternative. The final result is an overall ranking of the decision alternatives. This method incorporates the decision makers' knowledge/experience in AHP evaluation. The AHP method comprises decomposition, comparative subjective judgment and synthesis.

According to Saaty [46] and interpretation of [27], let $C_{1}, \ldots, C_{m}$ be $m$ decision criteria and $W=\left(w_{1}, \ldots, w_{m}\right)^{T}$ is their normalized relative importance weight vector as a result of the pairwise comparison, fulfilling the condition $\sum_{j=1}^{m} w_{j}=1$ and $w_{j} \geq 0$ for $j=1, \ldots, m$. The pairwise comparison among the $m$ decision criteria could be carried out by collecting expert opinions or by the decision maker's opinion. The pairwise comparison levels are divided into scales numbered from 1 to 9 , where 1 means equal importance, 3 means moderate importance, 5 means strong importance, 7 means very strong importance, and 9 means extreme importance of one over the other. Scales numbered 2, 4, 6 and 8 imply intermediate values. For the inverse comparison, the reciprocal values were used. The result is an $m \times m$ pairwise comparison matrix in the following form:

$$
A=\left(a_{i j}\right)_{m \times m}=\begin{gathered}
C_{1} \\
C_{2} \\
\vdots \\
C_{m}
\end{gathered}\left[\begin{array}{cccc}
a_{11} & a_{12} & \cdots & a_{1 m} \\
a_{21} & a_{22} & \cdots & a_{2 m} \\
\vdots & \vdots & \cdots & \vdots \\
a_{m 1} & a_{m 2} & \cdots & a_{m m}
\end{array}\right]
$$

where $a_{i j}$ represents a quantified judgement on $w_{i} / w_{j}$ with $a_{i i}=1$ and $a_{i j}=1 / a_{j i}$ for $i, j=1, \ldots, m$. The matrix $A=\left(a_{i j}\right)_{m \times m}$ is consistent in a case of fulfilment of the following condition: $a_{i j}=a_{i k} a_{k j}$ for any $i, j, k=1, \ldots, m$. From the pairwise comparison matrix $A$, the weight vector $W$ is determined by the equation:

$$
A W=\lambda_{\max } W
$$

where $\lambda_{\max }$ is the maximum eigenvalue of $A$. There is a possibility that a decision maker is not able to make the consistent pairwise comparisons. Pairwise comparison matrix $A$ needs to possess an acceptable consistency level, named consistency ratio (CR), and checked by the following equation:

$$
C R=\frac{\frac{\left(\lambda_{\max }-n\right)}{(n-1)}}{R I}
$$

where $R I$ represents the random inconsistency index and $n$ represents the number of alternatives. The $R I$ for pairwise comparison index of the fourth, fifth, and sixth order are $0.85,1.12$ and 1.15, respectively, according to Saaty [47]. If the $C R \leq 0.1$, the pairwise comparison matrix is thought to have an acceptable level of consistency in accordance to $[45,46]$.

The decision alternatives are being compared according to the pairwise principle with each decision criterion in the same way as criteria. Upon completing the calculations, the weights of the decision criteria and the weights of decision alternatives with respect to 
each criterion are recorded. In the next calculation step, the overall weight of each decision alternative with respect to the decision goal can be generated using the simple additive weighting (SAW) method as per Hwang and Yoon [48], described in the following equation:

$$
w_{A_{i}}=\sum_{j=1}^{m} w_{i j} w_{j}, i=1, \ldots, n
$$

where the $w_{j}(j=1, \ldots, m)$ are the decision criteria weights, the $w_{i j}(i=1, \ldots, n)$ are the decision alternatives weights in respect to criterion $j$, and $w_{A_{i}}(i=1, \ldots, n)$ are the overall weights of decision alternatives. The best alternative is the one with the best overall weight $w_{A_{i}}$ with respect to the decision goal. The AHP calculation will be carried out by AHP-OS software developed by Goepel [49].

\section{Experimental Investigation and Results}

This study covers a set of twenty-nine sea-going merchant vessels intended for unrestricted navigation and built in the same shipyard. All of the studied vessels were made of shipbuilding grade steel, built on a slipway and longitudinally launched into the sea. After launching, the vessels were outfitted and commissioned while berthed on the outfitting piers. At the stage of substantial completion and seaworthiness, the vessels were transferred to the repair shipyard for dry-docking purposes, by their own propulsion or, very seldom, by towing.

\subsection{DEA Model Presentation}

The studied vessels sets were marked from DMU01 to DMU29 and consisted of 13 (from DMU15 to DMU27) chemical tankers and 16 roll-on/roll-off (RO-RO) vessels (from DMU01 to DMU14 and DMU28 and DMU29) of different sizes. The vessels were evaluated by their data which included: Gross tonnage, underwater hull area, scope of the steelwork job, dry-dock rent and services costs, steelwork/coating costs, crew number, crew cost, vessel transfer cost, delays cost and dry-docking duration. The vessels' data set is homogenous and represented with figures ready for quantitative analysis.

This study also covered the four repair shipyards. They have different dry-docking facilities (floating dry-docks and engraved dry-docks). In order to reach these facilities, between one and three days of steaming are necessary. The repair shipyards/dry-docks were assessed against the following criteria: meteorological criterion, transfer/logistic criterion, hull damage criterion, dry-dock working conditions, dry-docking price level, and the vessel's waiting time, which occurred before the dry-docking commencement.

The proposed performance measurement model was shown in Figure 1.

The performance measurement model was shown in a block diagram form. The data sets were divided in two groups: the quantitative data intended to use in DEA models, and the qualitative data for AHP model evaluation. The DEA models were going to be used for the vessels' dry-docking performance measurement, and AHP model was going to be used for dry-docking facilities ranking using several criteria against the dry-docks as alternatives.

The DEA data preparation step includes the dry-docking data in order to create homogenous data sets for all the studied vessels. It was concluded that there was no missing data, and all data were collected in the same manner. Inputs and outputs were set upon their nature - technical data (area, volume) were set as inputs, and cost data were set as outputs. The input data were prepared in a manner to avoid the uncontrollable inputs. The output data were scaled in form of their reciprocals in order to follow the DEA principle that inputs tend to decrease, and outputs tend to increase, as per [40-44]. The DEA model was output oriented, according to the managerial intention to reduce dry-docking expenses. 


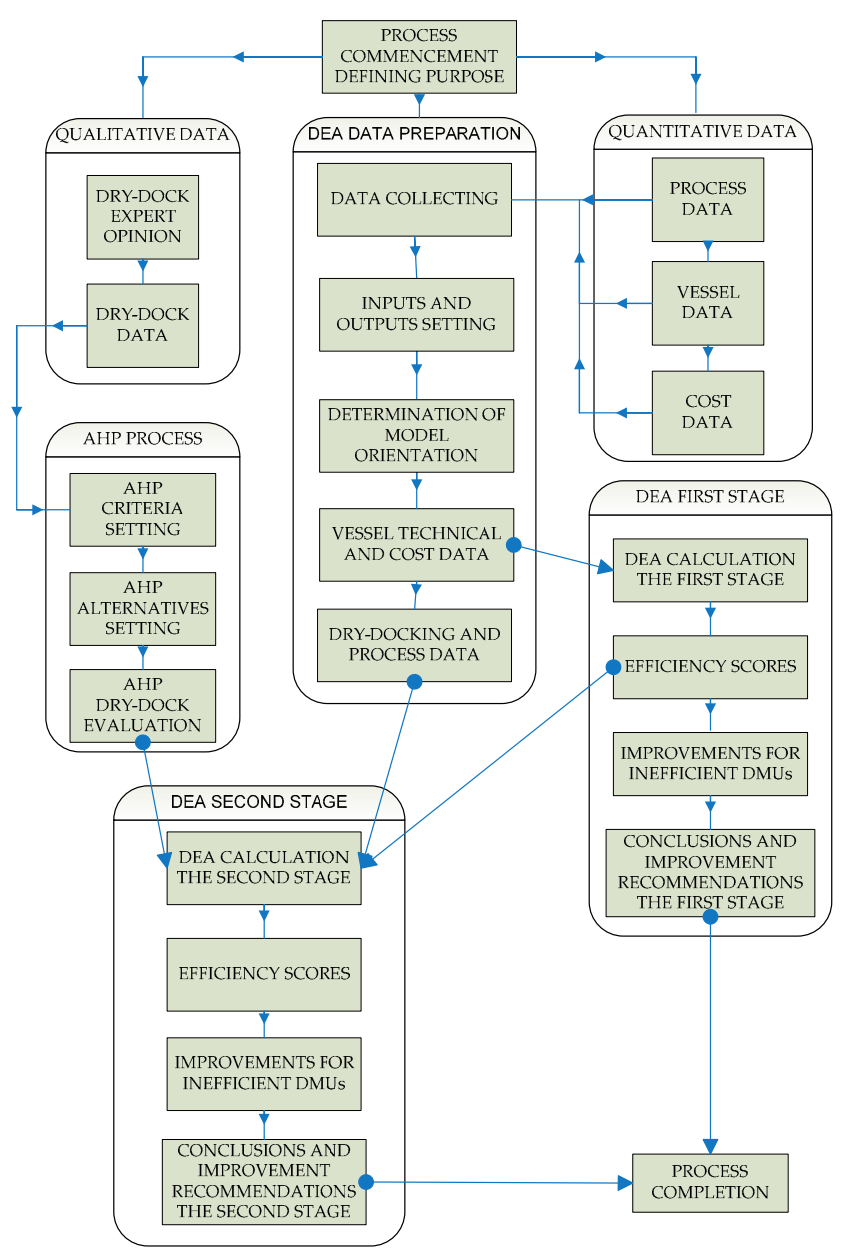

Figure 1. Performance measurement model.

\subsection{DEA Calculations, the First Step}

The first step DEA calculation was carried out with inputs: steelwork scope and gross tonnage quotient, marked as (I)CUTGT, which encourages less steelwork with greater gross tonnage, and the vessel's underwater part area subjected to coating multiplied by the time spent afloat after launching was marked as (I)AREATIME. The outputs were: dry-dock rent and services cost, marked as (O)DDOCK, and the cost of steelwork and coating activities during dry-docking, marked as (O)WORK. These outputs were scaled by putting their reciprocals into the DEA calculation. This DEA calculation resulted in the dry-docking efficiency score for every DMU. This efficiency score was based on the DMUs technical and cost data.

As a first step, the DEA calculation data descriptive statistics are shown in Table 1.

Table 1. The first step-DEA calculation data (before scaling) descriptive statistics.

\begin{tabular}{ccccc}
\hline & \multicolumn{2}{c}{ Inputs } & \multicolumn{2}{c}{ Outputs } \\
\hline & (I)CUTGT & (I)AREATIME & (O)DDOCK & (O)WORK \\
\hline Max. Value & 6.546 & 31607 & 32.430 & 52.137 \\
Min. Value & 2.610 & 9778 & 15.844 & 15.808 \\
Average Value & 4.660 & 19584 & 23.452 & 32.941 \\
St. Deviation & 1.480 & 6206 & 5.141 & 10.572 \\
\hline
\end{tabular}

Source: author's calculation.

The calculation was carried out by the output oriented CCR (CCR-O) and BCC (BCC-O) models. There are seven efficient DMUs in CCR-O model, and they were: DMU05, DMU06, 
DMU08, DMU17, DMU19, DMU21 and DMU22, and they represent the benchmarks for the inefficient DMUs. These efficient DMUs create the CCR efficient frontier and are peers for inefficient DMUs improvements. The CCR-O efficient DMUs are samples of the best overall performance in transforming inputs into outputs, and they are technically efficient. The BCC-O model results show the nine efficient DMUs. These are all the CCR-O efficient DMUs plus DMU14 and DMU26. They create the BCC efficient frontier and show the local efficiency as well as the managerial capability to organize the process. The efficiency scores obtained are shown in Figure 2.

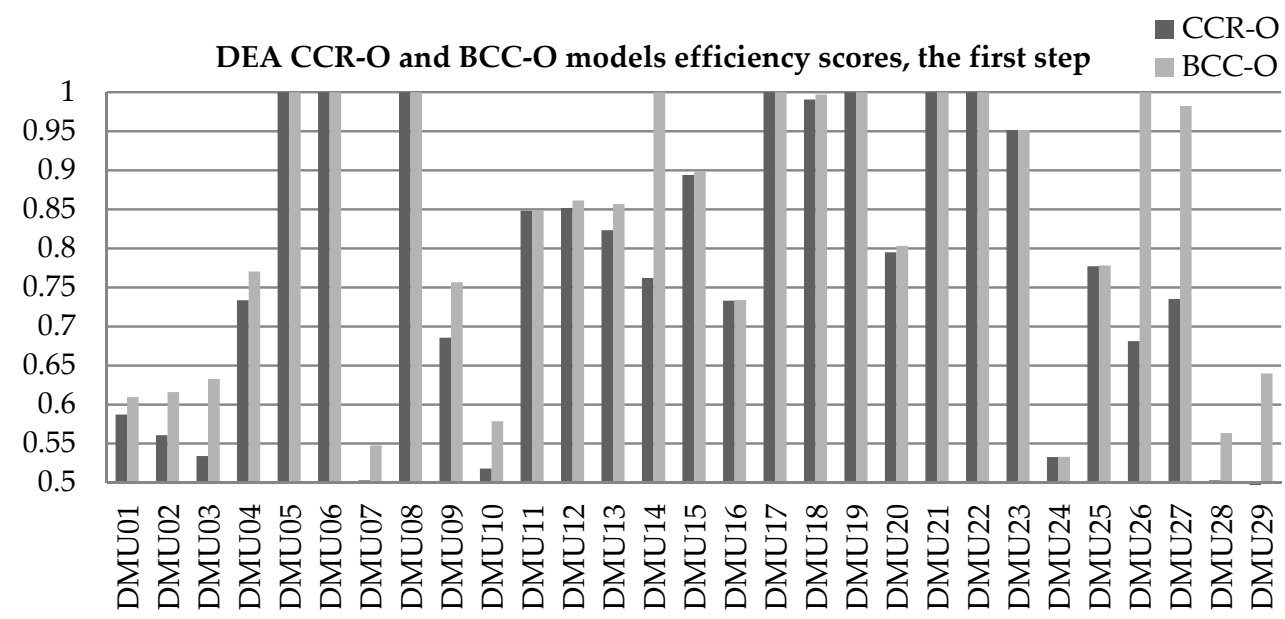

Figure 2. CCR-O and BCC-O efficiency scores, the first step.

The CCR-O and BCC-O models' results represent efficiency in the input-output transformation for the twenty-nine subjected vessels in relation to the chosen inputs and outputs. The results obtained in the first DEA step calculation were inputs for the second step DEA calculations.

In the first step, the input/output selection is focused on the dry-docking only, which means that technical data such as compensated gross tonnage, under water part area and scope steelwork as inputs are put into relationship with dry-dock and work costs as outputs. Therefore, it could be concluded that the first step calculation determines the efficiency occurring during dry-dock only, not including the wider picture of the dry-docking project.

\subsection{Dry-Docking Facilities Evaluation, the AHP Method}

Dry-docking facilities have different criteria $\left(C_{j}\right)$ which needs to be considered for their evaluation. Namely, there could be a difference in transfer and logistics conditions, and meteorological conditions could also impact the dry-docking performance and increase its cost. There are working conditions that need to be additionally considered, such as vessel/dry-dock clearance and hull damages, because some facilities are more prone to damage the vessel's hull, mainly in the form of indents and scratches. The waiting time spent on the anchor before the dry-docking commencement needs to be evaluated as well. The price levels were put into consideration. There were four facilities, which represent alternatives $\left(\mathrm{A}_{\mathrm{i}}\right)$ and they are marked as $\mathrm{A}, \mathrm{B}, \mathrm{C}$, and D. The AHP hierarchy is shown in Figure 3. 


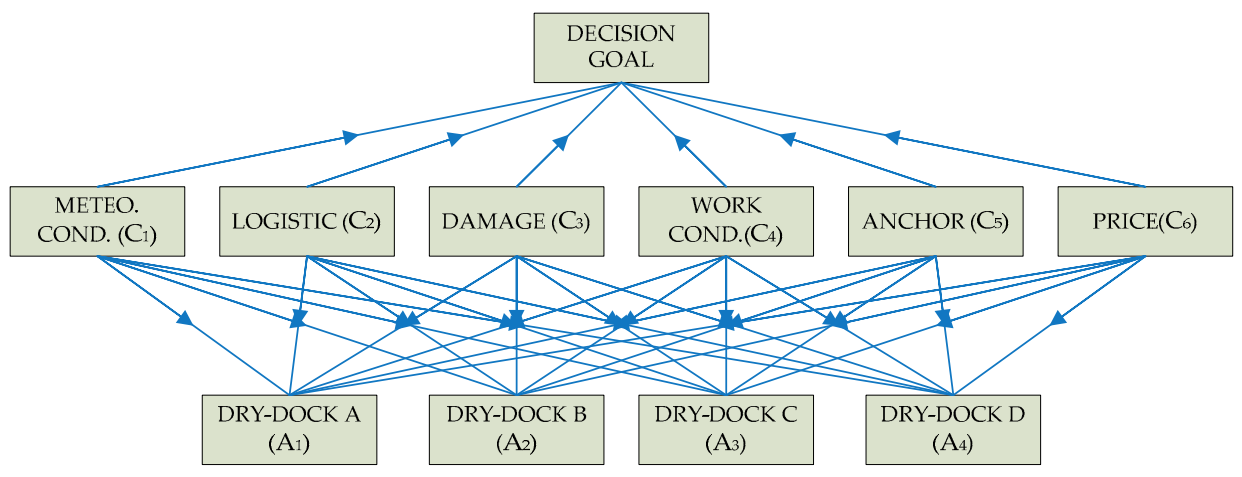

Figure 3. AHP hierarchy dry-docks evaluation.

Following the AHP hierarchy, the results were obtained, as shown in Table 2.

Table 2. AHP evaluation results.

\begin{tabular}{ccccccc}
\hline \multirow{2}{*}{ Decision Goal } & Criteria & Global Priority of Criteria & \multicolumn{4}{c}{ Alternatives } \\
\cline { 4 - 7 } & & & Dry-Dock A & Dry-Dock B & Dry-Dock C & Dry-Dock D \\
\hline & Meteo. & 0.398 & 0.200 & 0.200 & 0.078 & 0.522 \\
Optimal & Logistics & 0.078 & 0.561 & 0.271 & 0.115 & 0.052 \\
Dry-Docking & Damage & 0.255 & 0.053 & 0.549 & 0.297 & 0.102 \\
Facility & Work. & 0.153 & 0.282 & 0.579 & 0.081 & 0.057 \\
& Prilce & 0.051 & 0.102 & 0.058 & 0.331 & 0.509 \\
\hline & Anchor & 0.065 & 0.069 & 0.171 & 0.359 & 0.401 \\
\hline
\end{tabular}

Source: author's calculation.

The alternatives were evaluated against the pre-set criteria. Table 2 shows: (i) a list of criteria with their global priorities as criteria pairwise comparison result; (ii) the alternatives with their weights against each particular criterion; and (iii) the alternatives' overall weights as the AHP process result. According to the AHP comparison process carried out, the dry-dock facilities ranking is the following (with scores/normalized scores in brackets): Dry-dock B (0.343/1); Dry-dock D (0.299/0.872); Dry-dock A (0.190/0.554); and Dry-dock C $(0.168 / 0.490)$. These ranking results will be used in the second step DEA calculation.

\subsection{DEA Calculations, the Second Step}

The second step DEA calculation used dry-docking and process data with three inputs: combined input consisting of dry-docking duration in days divided by dry-dock facility ranking according to $\mathrm{AHP}$, marked (I)AHPDAY, created in order to encourage shorter dry-docking periods and higher AHP rating. The second combined input consisted of CCR-O and BCC-O models efficiency scores from DEA first step calculation, marked (I)EFF, which were scaled and multiplied. The crew number enlisted on board of the vessel versus optimal crew number was marked (I)CREWRATIO. The outputs were: crew cost marked (O)CREW and costs which included: the cost of vessel transfer including crew and waiting time on the anchor, as well as the cost of the enlisted crew due to the vessel's delay in dry-dock, and marked (O)TRANSF. The outputs were scaled by taking their reciprocals in order to follow the rule that outputs in DEA models tend to increase. The data set descriptive statistics are shown in Table 3. 
Table 3. The second step-DEA calculation data descriptive statistics.

\begin{tabular}{cccccc}
\hline & (I)AHPDAY & (I)EFF & (O)CREWRATIO & (O)CREW & (O)TRANSF \\
\hline Max. Value & 83.333 & 3.630 & 2.169 & 91.065 & 88.511 \\
Min. Value & 23.324 & 1.000 & 1.096 & 32.241 & 4.518 \\
Average Value & 43.376 & 1.845 & 1.563 & 60.878 & 20.955 \\
St. Deviation & 17.220 & 0.938 & 0.302 & 15.945 & 18.310 \\
\hline
\end{tabular}

Source: author's calculation.

In the second step of the DEA calculation, the CCR-O and BCC-O models were used. It could be noted that the CCR-O model calculation found six efficient DMUs and the BCC-O model calculation found eight efficient DMUs. The CCR-O-efficient DMUs were: DMU04, DMU08, DMU09, DMU15, DMU18, and DMU21. The BCC-O efficient DMUs were all the CCR-O efficient DMUs plus DMO06 and DMU14. Both models' efficiency scores were compared for each DMU and shown in Figure 4.

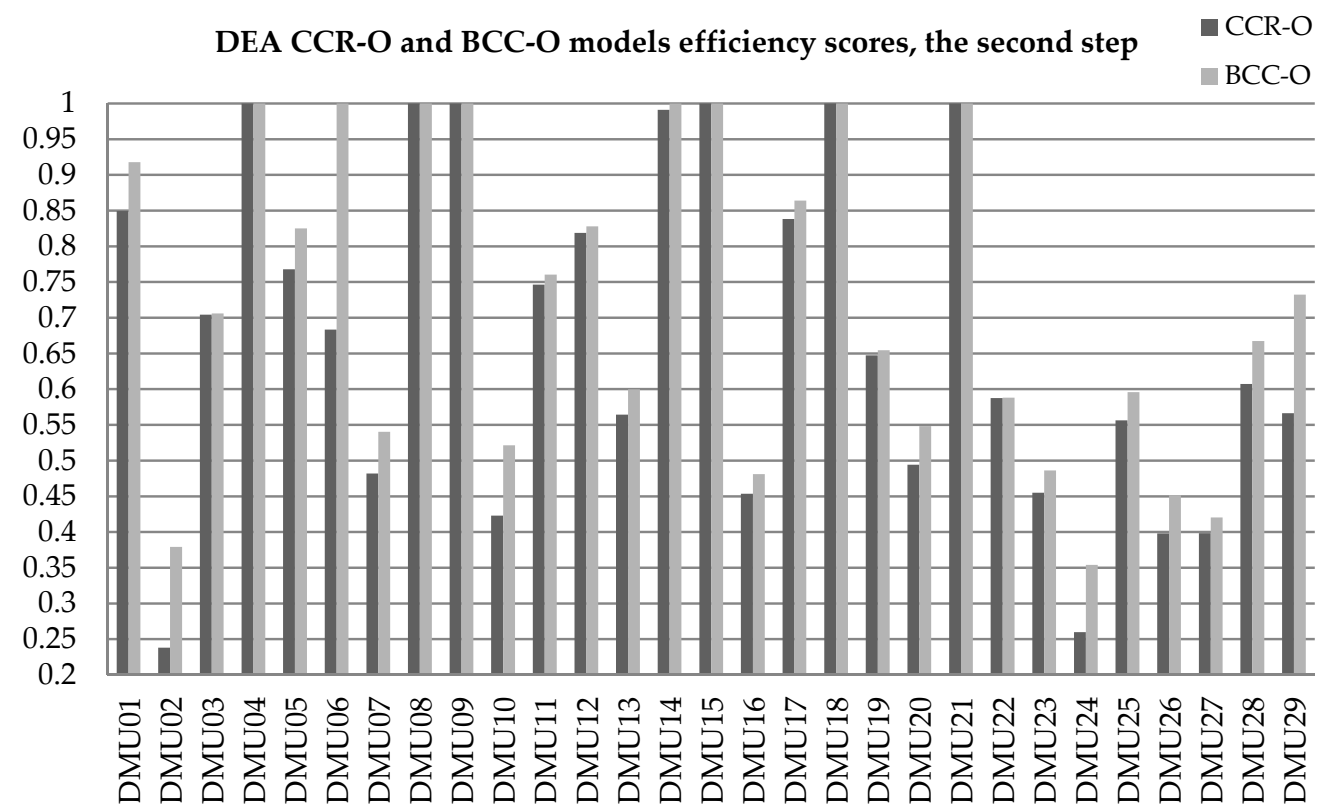

Figure 4. CCR-O and BCC-O efficiency score, the second step DEA.

\subsection{Overall Calculations Results}

Overall calculation results of descriptive statistics covering both steps of the developed DEA dry-docking performance measuring model are shown in Table 4. It could be noted that the DEA models used were good in "filtering" the DMUs. Namely, there were seven and six efficient DMUs out of 29 DMUs for CCR-O models. For the BCC-O models, there were nine and eight efficient DMUs for the first and second DEA calculation step. The average and minimum efficiency scores show that both steps discriminated the DMUs in a proper way, and consequently, the sources of inefficiency could be identified.

The efficiency scores obtained using the developed model, followed by the DMUs information related to vessel's type and dry-docking place including an average efficiency score, are presented in Table 5. The presented data show the benchmark DMUs. The efficiency scores are presented by the DMU and DEA calculation step. 
Table 4. Calculations results of the descriptive statistics: the first and second step of the DEA, in addition to CCR-O and BCC-O models.

\begin{tabular}{|c|c|c|c|c|}
\hline \multirow[b]{2}{*}{ DEA Model } & \multicolumn{2}{|c|}{ DEA, the First Step } & \multicolumn{2}{|c|}{ DEA, the Second Step } \\
\hline & CCR-O & BCC-O & CCR-O & BCC-O \\
\hline Total no. of DMU & 29 & 29 & 29 & 29 \\
\hline No. of Efficient DMU & 7 & 9 & 6 & 8 \\
\hline No. of Inefficient DMU & 22 & 20 & 23 & 21 \\
\hline Efficiency Mean Value & 0.7746 & 0.8262 & 0.6735 & 0.7215 \\
\hline Efficiency Standard Deviation & 0.1849 & 0.1687 & 0.2367 & 0.2190 \\
\hline Maximum Efficiency Score & 1 & 1 & 1 & 1 \\
\hline Minimum Efficiency Score & 0.4634 & 0.5330 & 0.2380 & 0.3540 \\
\hline No. of DMUs with Efficiency Under Mean score (\%) & $14(48 \%)$ & $13(45 \%)$ & $15(52 \%)$ & $15(52 \%)$ \\
\hline
\end{tabular}

Table 5. Overall calculation results.

\begin{tabular}{lccccccc}
\hline & & & \multicolumn{2}{c}{ DEA First Step } & DEA Second Step & DEA \\
\hline DMU & Type & Dock & CCR-O & BCC-O & CCR-O & BCC-O & $\begin{array}{c}\text { Average } \\
\text { Efficiency }\end{array}$ \\
\hline DMU01 & RO & B & 0.5871 & 0.6095 & 0.8495 & 0.9177 & 0.7409 \\
DMU02 & RO & A & 0.5609 & 0.6159 & 0.2380 & 0.3792 & 0.4485 \\
DMU03 & RO & B & 0.5341 & 0.6327 & 0.7043 & 0.7060 & 0.6443 \\
DMU04 & RO & A & 0.7335 & 0.7703 & 1 & 1 & 0.8760 \\
DMU05 & RO & C & 1 & 1 & 0.7679 & 0.8252 & 0.8983 \\
DMU06 & RO & C & 1 & 1 & 0.6836 & 1.0000 & 0.9209 \\
DMU07 & RO & B & 0.5029 & 0.5478 & 0.4819 & 0.5402 & 0.5182 \\
DMU08 & RO & B & 1 & 1 & 1 & 1 & 1 \\
DMU09 & RO & B & 0.6855 & 0.7566 & 1 & 1 & 0.8605 \\
DMU10 & RO & B & 0.5179 & 0.5786 & 0.4231 & 0.5216 & 0.5103 \\
DMU11 & RO & B & 0.8482 & 0.8482 & 0.7464 & 0.7605 & 0.8009 \\
DMU12 & RO & B & 0.8517 & 0.8613 & 0.8187 & 0.8279 & 0.8399 \\
DMU13 & RO & B & 0.8233 & 0.8566 & 0.5643 & 0.5999 & 0.7110 \\
DMU14 & RO & B & 0.7621 & 1 & 0.9911 & 1 & 0.9383 \\
DMU15 & CT & A & 0.8941 & 0.8983 & 1 & 1 & 0.9481 \\
DMU16 & CT & C & 0.7331 & 0.7339 & 0.4535 & 0.4812 & 0.6004 \\
DMU17 & CT & A & 1 & 1 & 0.8384 & 0.8640 & 0.9256 \\
DMU18 & CT & A & 0.9907 & 0.9971 & 1 & 1 & 0.9969 \\
DMU19 & CT & A & 1 & 1 & 0.6473 & 0.6546 & 0.8255 \\
DMU20 & CT & A & 0.7951 & 0.8034 & 0.4941 & 0.5484 & 0.6603 \\
DMU21 & CT & A & 1 & 1 & 1 & 1 & 1 \\
DMU22 & CT & C & 1 & 1 & 0.5875 & 0.5882 & 0.7939 \\
DMU23 & CT & A + B & 0.9515 & 0.9515 & 0.4550 & 0.4863 & 0.7111 \\
DMU24 & CT & C & 0.5328 & 0.5330 & 0.2598 & 0.3540 & 0.4199 \\
DMU25 & CT & B & 0.7771 & 0.7781 & 0.5564 & 0.5959 & 0.6768 \\
DMU26 & CT & B & 0.6813 & 1 & 0.3979 & 0.4515 & 0.6327 \\
DMU27 & CT & D & 0.7350 & 0.9825 & 0.3983 & 0.4204 & 0.6341 \\
DMU28 & RO & B & 0.5031 & 0.5635 & 0.6073 & 0.6673 & 0.5853 \\
DMU29 & RO & A & 0.4634 & 0.6398 & 0.5665 & 0.7325 & 0.6005 \\
\hline
\end{tabular}

The calculation data follow the logic established in the developed model shown in Figure 1. The first step calculations are based on the data related to the vessels' gross tonnage, and scope of steelwork and coating works. The outputs are expressed in cost, which depends on the scope of work, dry-docking duration and place of dry-docking. The second step calculations deal with the factors depending on the chosen dry-dock and scope of unresolved work not directly linked to the dry-docking, and the cost of delays which occurred before the dry-docking commencement and during the dry-docking. The efficiency scores obtained from the first step calculations and dry-dock facilities ranking are inputs for the second stage calculation. The average efficiency score obtained by calculating 
the four DEA models could be a guideline to the dry-docking project efficiency assessment. In this particular case, the overall efficient DMUs are DMU08 and DMU21, and they are benchmarks for all the other considered DMUs. The exception is DMU23, which was dry-docked in two dry-docks due to dry-dock business difficulties, and this DMU was excluded for dry-dock facilities ranking. Despite this, the model recognized it as quite highly efficient (0.9515 and 0.9515$)$ in the technical performance, and of low efficiency in the part of the process that includes delays, transfer and crew costs (0.4550 and 0.4863$)$ due to dry-dock change and related delays, and time-related costs.

The dry-docking facilities ranking with descriptive statistics, considering data from Tables 2 and 5 , is presented in Table 6 .

Table 6. Dry-dock facilities ranking.

\begin{tabular}{|c|c|c|c|c|c|}
\hline & Dry-Dock & $\mathbf{A}$ & B & $\mathrm{C}$ & D \\
\hline AHP & Normalized Score & 0.554 & 1 & 0.490 & 0.872 \\
\hline \multirow{4}{*}{ DEA } & Average Efficiency & 0.8090 & 0.7276 & 0.7267 & 0.6341 \\
\hline & Standard Deviation & 0.1953 & 0.1540 & 0.2131 & $\mathrm{~N} / \mathrm{A}$ \\
\hline & Maximum Score & 1 & 1 & 0.9209 & 0.6341 \\
\hline & Minimum Score & 0.4485 & 0.5103 & 0.4199 & 0.6341 \\
\hline \multirow{3}{*}{ Vessels } & Average Dry-dock Duration in Days & 9.11 & 9.85 & 12.00 & 13.00 \\
\hline & Total Delays on Anchor in Days & 6 & 2 & 0 & 0 \\
\hline & No. of Vessels & 9 & 13 & 5 & 1 \\
\hline
\end{tabular}

It could be noted that dry-dock A has got the highest average efficiency score, the shortest average dry-docking duration, the most of the delays on the anchor-six days in total - and the third AHP ranking. It could be concluded that dry-dock A is most efficient on average, but the delays downgrade it. Dry-dock B has the best AHP ranking, the second average efficiency score, its efficiency has the lowest standard deviation, and its delays on the anchor are two days in total for thirteen dry-docked vessels. According to Table 2, dry-dock B has got the best rating in damage (less damage) and working condition categories and second-best rating in meteorological and logistics conditions.

The efficient DMUs create the efficient frontier, and they are best practice units in the given set of data. The efficient DMUs do not have any data to be improved in their data sets, which is not the case with the inefficient ones. The inefficient DMUs requiring improvements increase as their distance from the efficient frontier increases. This is shown in Figures 5 and 6, where the relative improvements of the outputs and inputs are shown for the two DEA steps. Upon reaching the improved values of the inputs and outputs, the inefficient DMUs would become efficient. The DMUs improvement analysis is a helpful tool in searching for the inefficiency sources. The efficient DMUs were omitted from Figures 5 and 6, because their relative required improvement is zero. Figure 5 represents the DEA CCR-O model, as their first step shows the improvements mainly needed for the dry-dock rent and services (DDOCK) as well as the steelwork and coating activities (WORK) costs. The dry-dock rent and service costs are place and time dependent, which emphasizes the fact that a shorter dry-docking period is favourable.

Figure 6 shows the DEA CCR-O model, the second step, which includes the efficiency scores from the first DEA calculation step as well as the dry-docking facilities AHP evaluation and ranking. 
DEA CCR-O step 1 model, relative improvements for the inefficient DMUs

- AREATIME DDOCK - WORK

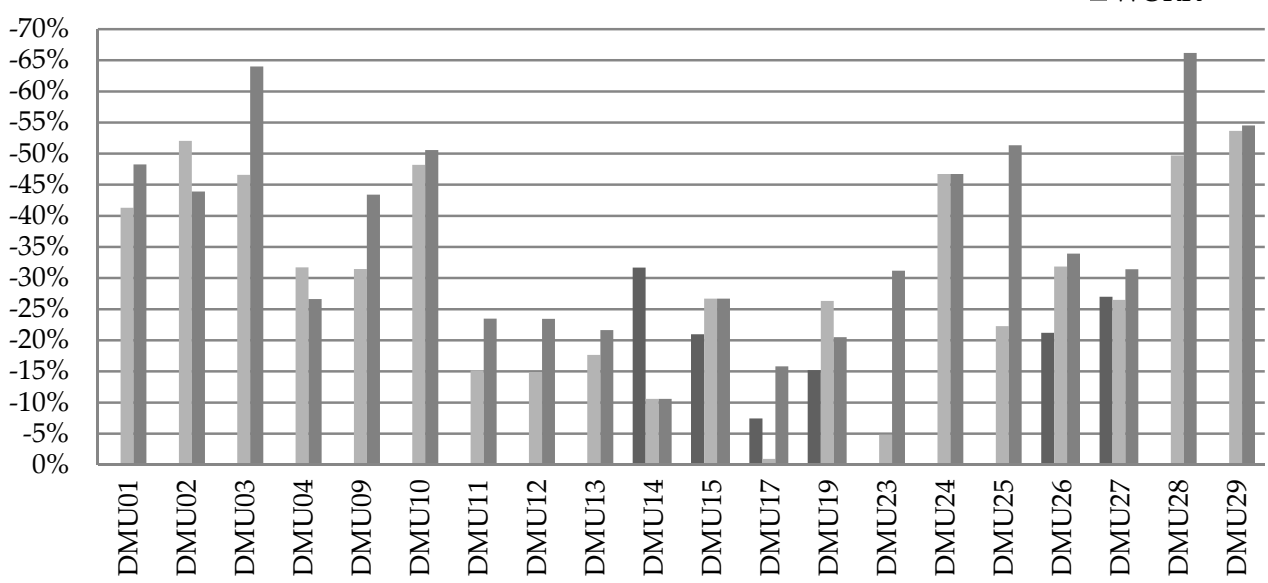

Figure 5. DEA CCR-O step 1 model: relative improvements for the inefficient DMUs.

DEA CCR-O step 2 model, relative improvements for the inefficient DMUs

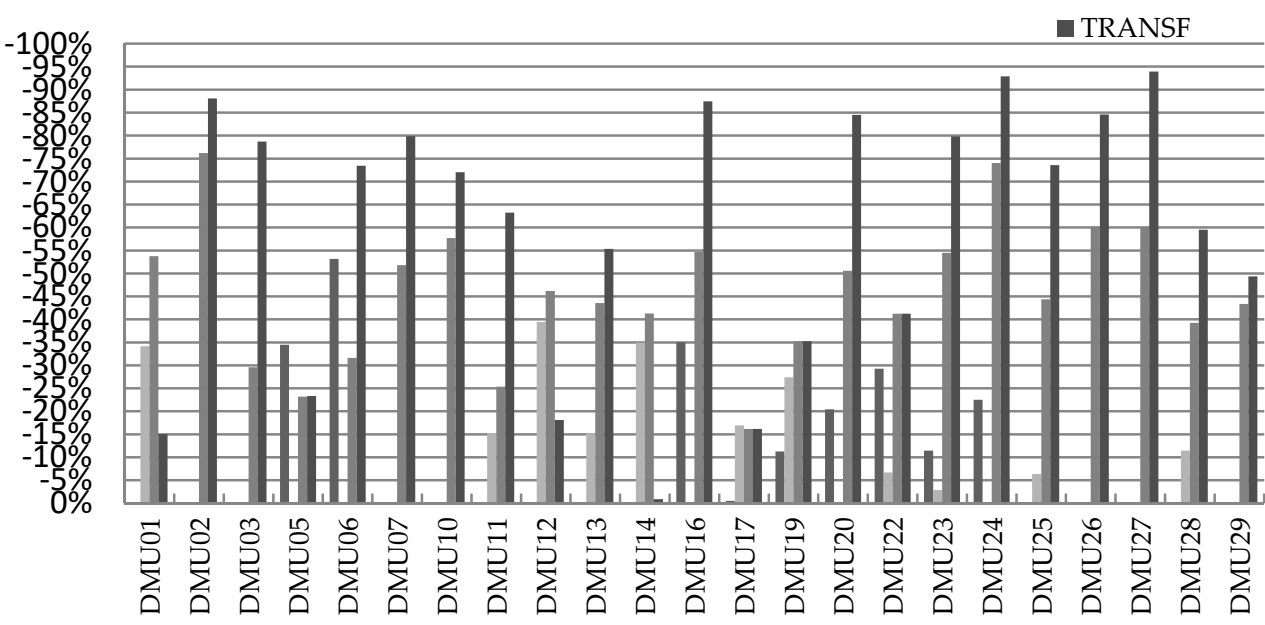

Figure 6. DEA CCR-O step 2 model: relative improvements for the inefficient DMUs.

The ratio between the actual and optimal crew number (CREW RATIO), the crew cost (CREW) and the cost which considers the vessel transfer and delays cost (TRANSF) are noted as the most influential factors for improvement. The inefficiency sources were found in the crew ratio/crew cost category, because this cost category could be avoided/reduced by decreasing the scope of the delayed works before the dry-docking project commencement while the vessel was in the shipyard. The transfer and delays cost could be reduced by avoiding the unnecessary delays on anchoring, reducing dry-dock waiting time, minimizing the delays in the dry-docking period by better dry-docking activities organization, and avoiding the dry-docking facilities in adverse weather seasons in order to reduce time delays.

\section{Discussion}

This paper introduces the dry-docking performance measurement model adjusted for the newbuilding vessels. For the model creation purpose, the DEA and AHP multi-criteria decision-making methods were employed. The DEA method deals with quantitative data, and the AHP method uses qualitative data. The introduced model consists of two DEA calculation steps. 
The first step uses vessel technical data such as gross tonnage, outer shell area to be treated in dry-dock, and the scope of steelwork activities as inputs. The outputs are set as dry-dock rent/services and the costs are related to the steelwork and coating works. The results of the first step DEA calculation are efficiency scores for all DMUs and the rate of improvements for the inefficient DMUs, which are all based on input/output data.

The second step DEA calculation uses data related to logistics, vessels' transfer, and efficiency scores from the first step calculation, and the scope of the unresolved works in relation to the number of the crew members enlisted. This calculation also includes the dry-docking facilities AHP evaluation and ranking. The outputs consist of the costs related to the enlisted crew and transfer/delays during the dry-docking project. The second step DEA calculation ultimately assess the overall studied process performance. This results in efficiency scores for the DMUs, and in relative improvements needed for reaching the efficient frontier for the inefficient DMUs.

The performance measurement model recognized the sources of inefficiency, which could be the time-dependent variables such as various types of delays where the time period increased and the work scope remains the same. The delays could be categorized to organization-related and weather-related delays. There is also space for improvement in the scope of steelwork activities and in the reduction in the unresolved works from the shipyard. It should be emphasized that the introduced DEA/AHP model could indicate the inefficient DMUs, and the amounts of inefficiencies with proposals' inputs and/or outputs which need to be improved. For the recognition of inefficiency sources and their causes, the knowledge of the studied process is of paramount importance.

The introduced two-step DEA/AHP model could be a helpful managerial tool for measuring the dry-docking performance. This model has been tested on twenty-nine vessels/DMUs, and new DMUs can be added into the existing DMU set. If the new DMU is efficient, it can shift the efficient frontier, and make a new efficiency ranking, which gives an option for continuous improvement. In the case where the new DMU is not efficient, it will be compared with the existing data set, and improvements in order to reach the efficient frontier will be calculated.

This model is a combination of two reliable and proven methodologies used for efficiency measurement based on qualitative and quantitative data related to the newbuilding dry-docking. The model results in the DMUs' performance measurement, establishing the efficient frontiers and calculating the improvement reached for the inefficient DMUs in order to reach the efficient frontier for both calculation steps. Consequently, the sources of inefficiency were detected, both in the technical and organizational part of the studied process. If a new DMU is added into the model established with the present data set/DMUs, it could cause changes in efficiency results. In case the new DMU is efficient, it will become a new benchmark and shift the efficient frontier. This could lead to a continuous improvement process. On the other hand, if the DMU is inefficient, the calculations of necessary improvements will be carried out, and the sources of inefficiency examined.

This research could be continued by using the network slack-based-measurement (Network SBM) DEA models.

Author Contributions: D.R. (Denis Rabar), D.R. (Danijela Rabar), D.P. equally contributed to the empirical analysis and writing. All authors have read and agreed to the published version of the manuscript.

Funding: This research received no external funding.

Institutional Review Board Statement: Not applicable.

Informed Consent Statement: Not applicable.

Data Availability Statement: The data presented in this study are available on request from the corresponding author.

Acknowledgments: This paper was a result of the scientific project "Accounting for the Future, Big Data and Economic Measurement supported by the Faculty of Economics and Tourism ‘Mijo 
Mirković"', from the Juraj Dobrila University of Pula. Any opinions, findings, and conclusions or recommendations expressed in this paper are those of the author and do not necessarily reflect the views of the Faculty of Economics and Tourism "Mijo Mirković" Pula. This work has been supported by the University of Rijeka (contract no. uniri-tehnic-18-33) and the Croatian Science Foundation under the project IP-2018-01-3739.

Conflicts of Interest: The authors declare no conflict of interest.

\section{References}

1. Kaune, J.E. The Art of Drydocking. Nav. Eng. J. 1976, 88, 51-62. [CrossRef]

2. House, D. Dry Docking and Shipboard Maintenance: A Guide for Industry; Routledge: Milton Keynes, UK, 2015. [CrossRef]

3. Naffisah, M.S.; Surjandari, I.; Rachman, A.; Palupi, R. Estimation of dry docking maintenance duration using artificial neural network. Int. J. Comput. Commun. Instrum. Eng. (IJCCIE) 2014, 1, 113-115. [CrossRef]

4. Surjandari, I.; Novita, R. Estimation model of dry docking duration using data mining. Int. J. Ind. Manuf. Eng. 2013, 7, $1588-1591$.

5. Surjandari, I.; Dhini, A.; Rachman, A.; Novita, R. Estimation of dry docking duration using a numerical ant colony decision tree. Int. J. Appl. Manag. Sci. 2015, 7, 164. [CrossRef]

6. Apostolidis, A.; Kokarakis, J.; Merikas, A. Modeling the Dry-Docking Cost-The Case of Tankers. J. Ship Prod. Des. 2012, 28, 134-143. [CrossRef]

7. Dev, A.K.; Saha, M. Dry-Docking Time and Labour. Int. J. Marit. Eng. 2018, 160. [CrossRef]

8. Koboević, Ž.; Bebić, D.; Kurtela, Ž. New approach to monitoring hull condition of ships as objective for selecting optimal docking period. Ships Offshore Struct. 2018, 14, 95-103. [CrossRef]

9. Gavalas, D.; Syriopoulos, T.; Tsatsaronis, M. Assessing key performance indicators in the shipbuilding industry; an MCDM approach. Marit. Policy Manag. 2021, 1-29. [CrossRef]

10. Yang, Y.O.; Wang, G.F. Analysis of the Efficiency of Chinese Repair Shipbuilding Industry. J. Korea Port Econ. Assoc. 2017, 33, 117-134. [CrossRef]

11. Mayo, G.; Shoghli, O.; Morgan, T. Investigating Efficiency Utilizing Data Envelopment Analysis: Case Study of Shipyards. J. Infrastruct. Syst. 2020, 26. [CrossRef]

12. Rabar, D.; Pavletić, D.; Doboviček, S.; Vlatković, M. Dry-docking performance measurement model-multi criteria non parametric approach. Ships Offshore Struct. 2021, 1-8. [CrossRef]

13. Mous, A. A Study on the Competiveness of Ship Repair Industry in Busan Area Using AHP. Master's Thesis, Korea Maritime University, Busan, Korea, 2011.

14. Ho, W. Integrated analytic hierarchy process and its applications-A literature review. Eur. J. Oper. Res. 2008, 186, 211-228. [CrossRef]

15. Ho, W.; Ma, X. The state-of-the-art integrations and applications of the analytic hierarchy process. Eur. J. Oper. Res. 2018, 267, 399-414. [CrossRef]

16. Sinuany-Stern, Z.; Mehrez, A.; Hadad, Y. An AHP/DEA methodology for ranking decision making units. Int. Trans. Oper. Res. 2000, 7, 109-124. [CrossRef]

17. Feng, Y.; Lu, H.; Bi, K. An AHP/DEA method for measurement of the efficiency of R\&D management activities in universities. Int. Trans. Oper. Res. 2004, 11, 181-191. [CrossRef]

18. Yang, T.; Kuo, C. A hierarchical AHP/DEA methodology for the facilities layout design problem. Eur. J. Oper. Res. 2003, 147, 128-136. [CrossRef]

19. Arunyanart, S.; Pruekthaisong, S. Selection of Multi-Criteria Plant Layout Design by Combining AHP and DEA Methodologies. MATEC Web Conf. 2018, 192, 01033. [CrossRef]

20. Korpela, J.; Lehmusvaara, A.; Nisonen, J. Warehouse operator selection by combining AHP and DEA methodologies. Int. J. Prod. Econ. 2007, 108, 135-142. [CrossRef]

21. Sevkli, M.; Koh, S.C.L.; Zaim, S.; Demirbag, M.; Tatoglu, E. An application of data envelopment analytic hierarchy process for supplier selection: A case study of BEKO in Turkey. Int. J. Prod. Res. 2007, 45, 1973-2003. [CrossRef]

22. Zhang, X.; Lee, C.; Chen, S. Supplier evaluation and selection: A hybrid model based on DEAHP and ABC. Int. J. Prod. Res. 2012, 50, 1877-1889. [CrossRef]

23. Park, S.C.; Lee, J.H. Supplier selection and stepwise benchmarking: A new hybrid model using DEA and AHP based on cluster analysis. J. Oper. Res. Soc. 2018, 69, 449-466. [CrossRef]

24. Ghavami, S.M.; Borzooei, Z.; Maleki, J. An effective approach for assessing risk of failure in urban sewer pipelines using a combination of GIS and AHP-DEA. Process. Saf. Environ. Prot. 2020, 133, 275-285. [CrossRef]

25. Chen, A.; Zheng, P. A New Ship-Targeting Model for Ship Supervision Based on AHP-DEA Method. In Proceedings of the 2018 7th International Conference on Energy, Environment and Sustainable Development (ICEESD 2018), Shenzhen, China, 30-31 March 2018; Atlantis Press: Dordrecht, The Netherlands, 2018; pp. 918-926. [CrossRef]

26. Sueyoshi, T.; Shang, J.; Chiang, W.-C. A decision support framework for internal audit prioritization in a rental car company: A combined use between DEA and AHP. Eur. J. Oper. Res. 2009, 199, 219-231. [CrossRef]

27. Wang, Y.-M.; Liu, J.; Elhag, T.M.S. An integrated AHP-DEA methodology for bridge risk assessment. Comput. Ind. Eng. 2008, 54, 513-525. [CrossRef] 
28. Charnes, A.; Cooper, W.W.; Rhodes, E. Measuring the efficiency of decision making units. Eur. J. Oper. Res. 1978, 2, 429-444. [CrossRef]

29. Banker, R.D.; Charnes, A.; Cooper, W.W. Some Models for Estimating Technical and Scale Inefficiencies in Data Envelopment Analysis. Manag. Sci. 1984, 30, 1078-1092. [CrossRef]

30. Cooper, W.W.; Seiford, L.M.; Tone, K. Introduction to Data Envelopment Analysis and Its Uses With DEA-Solver Software and References; Springer Science \& Business Media: Berlin, Germany, 1998; pp. 243-245. [CrossRef]

31. Coelli, T.J.; Rao, D.S.P.; Battese, G.E. An Introduction to Efficiency and Productivity Analysis; Springer Science \& Business Media: New York, NY, USA, 1998; pp. 243-245. [CrossRef]

32. Mortimer, D. Competing Methods for Efficiency Measurement: A Systematic Review of Direct DEA vs. SFA/DFA Com-Parisons. 2002. Available online: https:/ / core.ac.uk/download/pdf/36962976.pdf (accessed on 7 March 2021).

33. Coelli, T.J.; Rao, D.S.P.; O’Donnell, C.J.; Battese, G.E. An Introduction to Efficiency and Productivity Analysis; Springer Science \& Business Media: Berlin, Germany, 2005; pp. 243-245. [CrossRef]

34. Kahraman, C. (Ed.) Fuzzy Multi-Criteria Decision Making: Theory and Applications with Recent Developments; Springer Science \& Business Media: Berlin, Germany, 2008; Volume 16, pp. 1-18. [CrossRef]

35. Velasquez, M.; Hester, P.T. An analysis of multi-criteria decision making methods. Int. J. Oper. Res. 2013, 10, 56-66.

36. Aruldoss, M.; Lakshmi, T.M.; Venkatesan, V.P. A survey on multi criteria decision making methods and its applications. Am. J. Inf. Syst. 2013, 1, 31-43. [CrossRef]

37. Korhonen, P.J.; Wallenius, J. Making Better Decisions. Int. Ser. Oper. Res. Manag. Sci. 2020, 294, 131-139. [CrossRef]

38. Banker, R.D.; Charnes, A.; Cooper, W.W.; Swarts, J.; Thomas, D. An introduction to data envelopment analysis with some of its models and their uses. Res. Gov. Non-Profit Account. 1989, 5, 125-163.

39. Sarkis, J. A comparative analysis of DEA as a discrete alternative multiple criteria decision tool. Eur. J. Oper. Res. 2000, 123, 543-557. [CrossRef]

40. Dyson, R.; Allen, R.; Camanho, A.; Podinovski, V.; Sarrico, C.; Shale, E. Pitfalls and protocols in DEA. Eur. J. Oper. Res. 2001, 132, 245-259. [CrossRef]

41. Golany, B.; Roll, Y. An application procedure for DEA. Omega 1989, 17, 237-250. [CrossRef]

42. Lovell, C.K.; Pastor, J.T.; Turner, J.A. Measuring macroeconomic performance in the OECD: A comparison of European and non-European countries. Eur. J. Oper. Res. 1995, 87, 507-518. [CrossRef]

43. Liu, W.B.; Meng, W.; Li, X.X.; Zhang, D.Q. DEA models with undesirable inputs and outputs. Ann. Oper. Res. 2009, 173, 177-194. [CrossRef]

44. Cook, W.D.; Tone, K.; Zhu, J. Data envelopment analysis: Prior to choosing a model. Omega 2014, 44, 1-4. [CrossRef]

45. Saaty, T.L. The analytic hierarchy process. In The Analytic Hierarchy Process; Saaty, T.L., Kearns, K.P., Eds.; McGraw-Hill.: New York, NY, USA; Elsevier: Amsterdam, The Netherlands, 1985; pp. 19-62.

46. Saaty, T.L. How to make a decision: The analytic hierarchy process. Eur. J. Oper. Res. 1990, 48, 9-26. [CrossRef]

47. Saaty, T.L. A scaling method for priorities in hierarchical structures. J. Math. Psychol. 1977, 15, 234-281. [CrossRef]

48. Hwang, C.L.; Yoon, K. Multiple Attribute Decision Making Methods and Applications A State-of-the-Art Survey; Springer: Berlin/Heidelberg, Germany, 1981. [CrossRef]

49. Goepel, K.D. Implementation of an Online Software Tool for the Analytic Hierarchy Process (AHP-OS). Int. J. Anal. Hierarchy Process. 2018, 10. [CrossRef] 